COMECHINGONIA. REVISTA DE ARQUEOLOGÍA Número 16, primer semestre de 2012, pp. 85-104, Córdoba

ISSN 0326-7911

\title{
LA CASA Y EL CAMPO EN LA QUEBRADA DE LOS CORRALES (EL INFIERNILLO, TUCUMÁN): REFLEXIONES SOBRE LA ESPACIALIDAD EN EL $1^{\circ}$ MILENIO d.C.
}

\author{
Eugenia Di Lullo \\ ${ }^{1}$ I.A.M. Facultad de Ciencias Naturales e IML. U.N.T. Buenos Aires 491, 4toC. 4000, San Miguel de Tucumán \\ E-mail: eugedl@gmail.com
}

Presentado el: 05/12/2011 - Aceptado 15/05/2012

\begin{abstract}
Resumen
La Quebrada de Los Corrales (El Infiernillo, Tucumán) es un yacimiento arqueológico cuyo lapso de ocupación más intenso se dio entre ca. 2100 y 1560 años AP. Aquí, las áreas agrícolas-pastoriles están separadas de las residenciales, situación que contrasta con otros sitios de la región del mismo periodo. En este sentido, el objetivo de este trabajo es comprender las condiciones que habrían generado la particular estructuración del espacio y las implicancias que tuvo esto a través del análisis de mapas realizados mediante SIG.
\end{abstract}

Palabras claves: Estructuración del espacio, Primer Milenio d.C., Sistemas de Información Geográfica.

\begin{abstract}
Quebrada de Los Corrales (El Infiernillo, Tucumán) is an archaeological site whose most significant period of occupation occurred during the first half of the First Millenium a. C., between ca. 2060 y 1560 años BP. Here, farming and dwelling areas are separated from each other as opposed to nearby sites from the same period where both share the same space. Therefore, the aim of this paper is to understand the conditions that may have generated this type of space structuring in Quebrada de Los Corrales and its implications through the analysis of maps generated by GIS.
\end{abstract}

Keywords: Space Structuring, First Millennium a. C, Geographic Information Systems.

\section{Introducción}

A nivel arqueológico, el Primer Milenio d. C. en el NOA implica un cambio social y económico que es acompañado por la proliferación de los primeros asentamientos estables en la región. Éstos, aunque en muchos casos similares, cuentan con algunas diferencias que podrían darnos pautas acerca de sus habitantes, ya que el espacio, entendido como una forma de producción cultural, se encuentra formado por elementos cargados de significados. En este sentido, la configuración espacial de la Quebrada de Los Corrales se presenta como un caso particular dentro de su contexto ya que el sector residencial se encuentra separado de las grandes extensiones agrícola-pastoriles, siendo que los sitios contemporáneos de la región presentan una escala y una organización distinta. 
La singularidad de este yacimiento nos ha llevado a indagarnos sobre las condiciones que incidieron en su singular estructuración, considerando que este proceso debió involucrar tanto decisiones conscientes como inconscientes, y que la construcción y experiencia del espacio, reprodujo las condiciones que lo generaron.

\section{El área de estudio y el estado de la cuestión.}

La zona de investigación corresponde a La Quebrada de Los Corrales que se encuentra a c.a.3000 msnm en el abra de El Infiernillo, Tucumán. El área conforma morfológicamente el límite norte del valle de Tafí y conecta a éste con el de Santa María, lugares que tienen diferencias ecológicas marcadas (Oliszewski et al. 2008) (Figura1)

La quebrada se constituye como un yacimiento arqueológico de altura (Oliszewski et al. 2008) ya que las evidencias de ocupación prehispánicas están integradas por una serie de

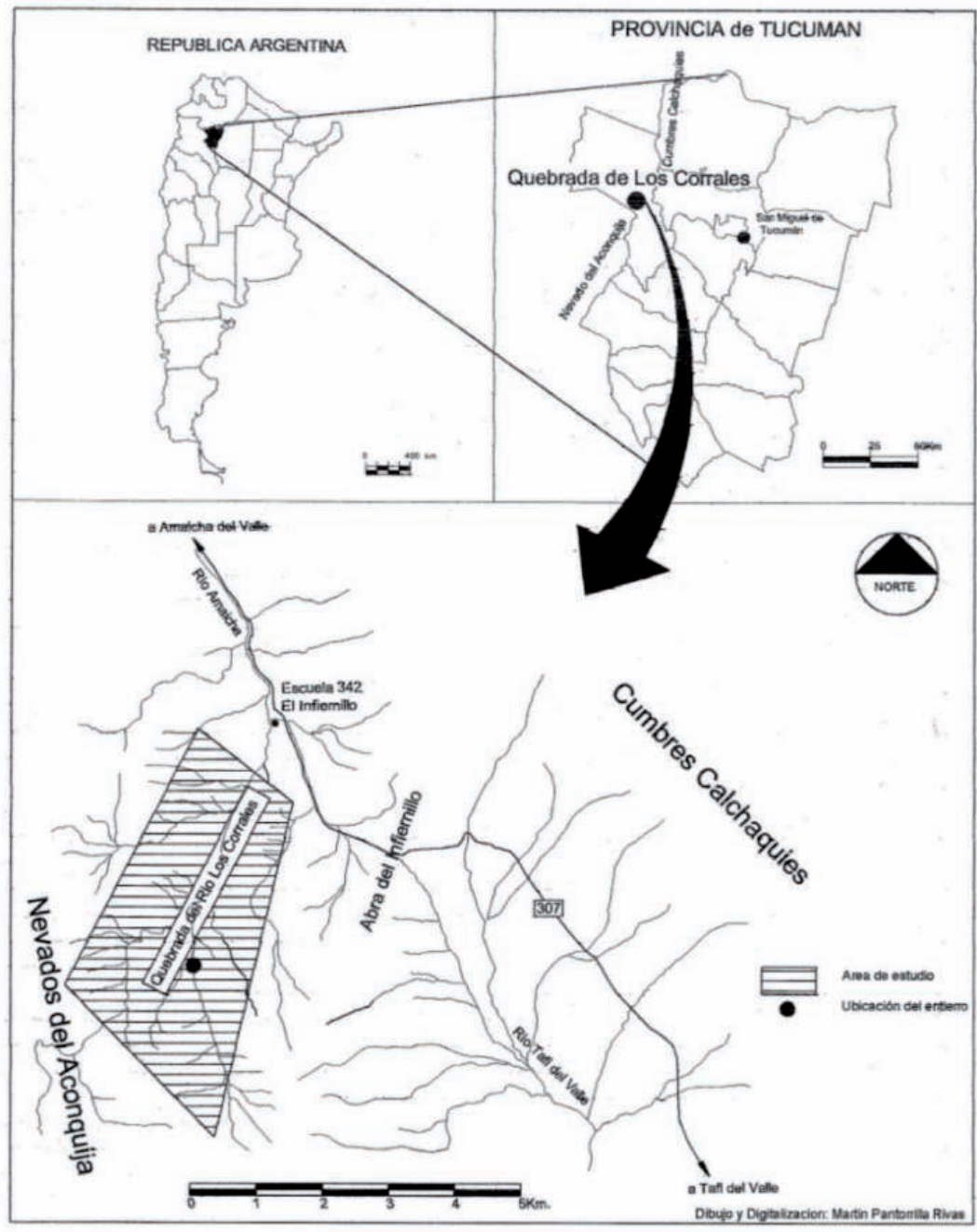

Figura 1. Ubicación de la Quebrada de Los Corrales, El Infiernillo, Tucumán. (Tomado de Oliszewski 2011) 
estructuras de distinto tipo distribuidas a lo largo de toda la cuenca del río. Se trata de dos cuevas en la cuenca inferior y media respectivamente, y numerosas estructuras agrícolas, pastoriles y residenciales en la cuenca media/superior (Figura 2).

Cueva de Los Corrales 1 (CC1) habría sido un locus multifuncional de ocupación esporádica que cuenta con dataciones de entre ca. 2100 y 630 años AP (Oliszewski et al. 2008; Di Lullo 2008). Por otra parte, Cueva de Los Corrales 2 (CC2) estuvo relacionada con actividades de caza y/o pastoreo y fue ocupada hacia ca. 1400 años AP (Olizsewski 2011).

En cuanto a las áreas de producción, se encuentran representadas por un sistema de andenerías que cubre aproximadamente 500ha y por numerosas estructuras circulares (probables corrales). Cabe destacar que los sistemas de cultivo no presentan conexión topográfica alguna con el curso fluvial del río de Los Corrales, lo cual permite inferir que tuvieron como única fuente de riego el manejo del agua de lluvia (Caria et al. 2006; 2009). En cuanto a los corrales, se han contabilizado cerca de 250 recintos de grandes dimensiones construidos en piedra y espacialmente asociados a los campos agrícolas.

Por otro lado, la zona residencial de la Quebrada de Los Corrales se ubica en el área meridional, contando con 85 unidades habitacionales que se encuentran agrupadas en ambas márgenes del río. Para su estudio, estos sectores se denominaron Puesto Viejo 1 (PV1) y Puesto Viejo 2 (PV2).Todas las estructuras tienen una configuración similar al denominado patrón "margarita" típico del valle de Tafí (Berberian y Nielsen 1988). Entre los materiales recuperados en superficie, se puede mencionar la presencia de abundante material lítico y cerámico. El primero se encuentra representado por núcleos, lascas y artefactos formatizados, mayoritariamente en materias primas locales -andesita y cuarzo- (Cruz et al. 2009). La cerámica se encuentra representada por fragmentos asignables a los estilos Tafí, Candelaria, Ciénaga, Condorhuasi y Vaquerías (Gramajo Bühler 2009).

En el año 2008 se realizaron excavaciones en una estructura (E1) de PV2. La ocupación inicial del recinto central se encuentra datada sobre carbón vegetal, entre $1710 \pm 30$ (UGAMS05795) y $1690 \pm 30$ años AP (UGAMS- 06598), mientras que la final se sitúa en $1600 \pm 25$ años AP (UGAMS- 06597, endocarpo de chañar) (Oliszewski et al. 2010a). Los hallazgos realizados apoyan la función doméstica de la estructura (Oliszewski et al 2010a)

Otra estructura excavada fue la denominada E2 de PV1. Allí fue rescatado un entierro directo de un joven-adulto con ajuar, cuyos restos óseos fueron fechados en $1560 \pm 25$ años AP (UGAMS- 04251) (Oliszewski et al. 2010b).

Si bien existen evidencias de ocupaciones humanas anteriores a ca. 3300 AP (Martínez et al 2011) y posteriores a ca. $600 \mathrm{AP}$ aproximadamente, la mayoría de los indicadores permiten establecer que la Quebrada de Los Corrales estuvo habitada con mayor énfasis hacia la primera mitad del Primer Milenio d. C., en especial entre ca. 2100 y 1560 años AP (Oliszewski et al. 2008; Oliszewski et al. 2010a; Oliszewski 2011).

Si bien sabemos que Puesto Viejo (PV) fue habitado hacia el Primer Milenio d. C., aún se desconoce cómo se fueron sucediendo las instalaciones allí. En este sentido, los datos tempranos empiezan a darnos algunas pautas sobre el proceso de poblamiento del área residencial. Éstos provienen del sector sur de PV1, denominado Taller. Se trata de un sitio a cielo abierto circunscripto por estructuras residenciales del Primer Milenio d. C., donde 
se halló en superficie abundante material lítico (Martínez et. al. 2011). Dos dataciones obtenidas sobre restos óseos animales de excavación, arrojaron edades de c.a 3330 y c.a 7420 años AP (AMS, CASI-UGA) (Martínez et al 2011). Estos datos, sumados a las características tecno-morfológicas de los artefactos, indican que este sector de la quebrada estuvo ocupada por poblaciones arcaicas relacionadas con actividades de caza, previo a la instalación en este sector de grupos agro-pastoriles sedentarios (Mauri y Martínez 2009). En este taller existen evidencias de actividades relacionadas a la molienda el consumo de fauna y la manufactura y mantenimiento de artefactos líticos que se suceden a largo de la secuencia estratigráfica, lo que refleja que este espacio fue usado recurrentemente a lo largo del tiempo, deviniendo finalmente en una instalación duradera (Martínez et al 2011).

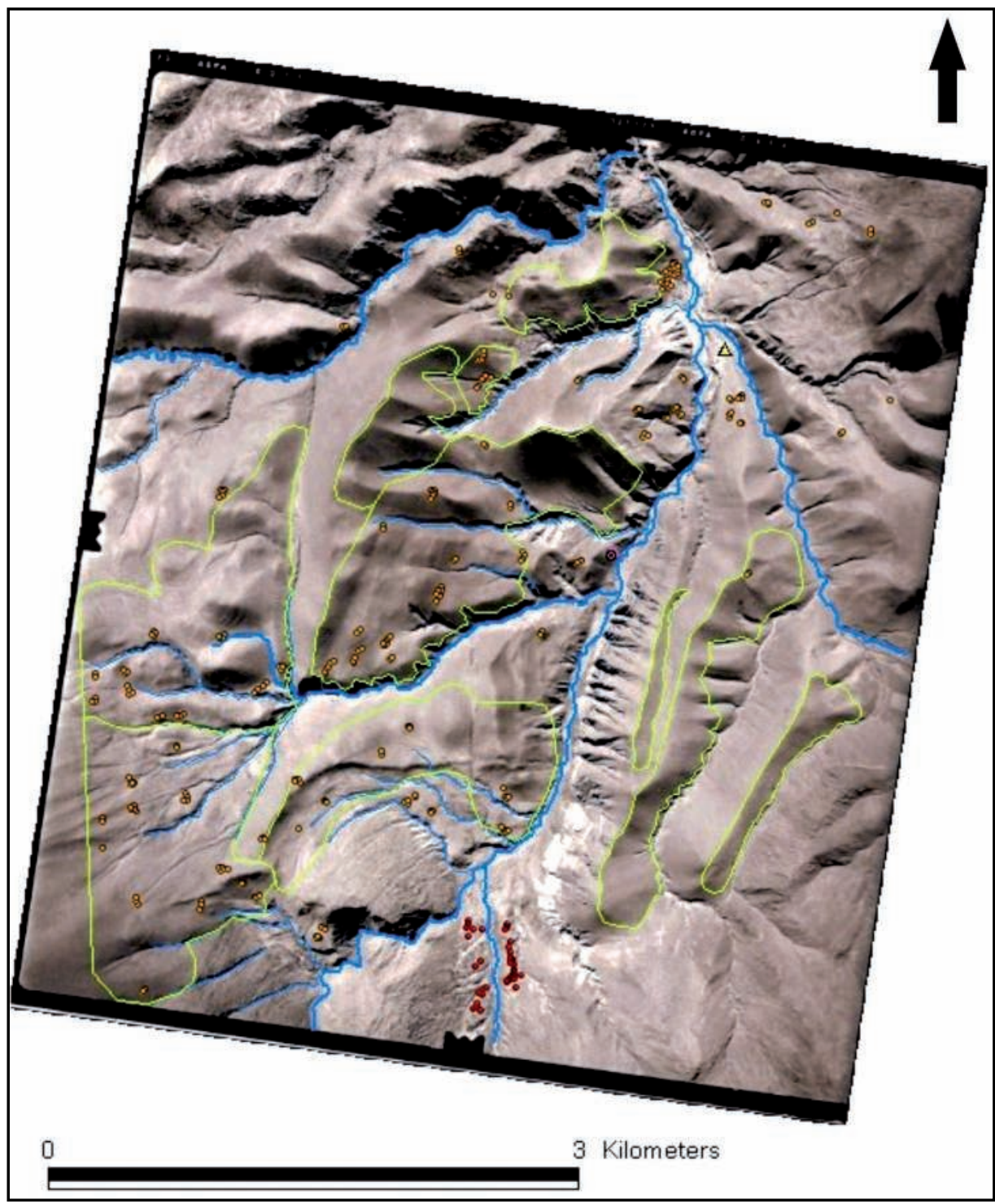

Figura 2. Quebrada de Los Corrales. En rojo, Puesto Viejo. En Rosa CC1. En naranja, corrales. En verde, andenería. 
Otro tema que se desconoce es si PV1 y PV2 fueron habitados simultáneamente o no, aunque si consideramos los intervalos de sus fechados, se puede hablar de que ambos estuvieron ocupados de forma sincrónica. A pesar de que esto debe corroborarse con más excavaciones y dataciones, actualmente se maneja la hipótesis de la sincronicidad (Oliszewski 2011). Del mismo modo, aunque no se cuenta por el momento con dataciones de los sectores productivos, se considera que corrales y andenes habrían funcionado durante el Primer Milenio d. C. ya que no se tiene ningún tipo de evidencia que indique lo contrario (Oliszewski et al. 2010a; Oliszewski 2011).

\section{El espacio: constructor y construcción social}

Este trabajo parte de la idea que el ser humano tiene un rol activo en la construcción e interpretación del mundo que lo rodea, siendo el paisaje una entidad que existe en tanto es percibido, experimentado y contextualizado por las personas (Ashmore y Knapp 2000).

En relación a este tema, las investigaciones arqueológicas han tomado especial interés en la dimensión construida o social del paisaje (sensu Criado Boado 1999), destacando su valor como medio para interpretar a la sociedad, en tanto producción cultural que ordena y crea las relaciones entre los individuos que lo viven.

El espacio social o espacialidad (sensu Acuto y Gifford, 2007) se encuentra materialmente constituido. A su vez, al estar socialmente construida, esa materialidad se encuentra cargada de significados, de mensajes, que indican su rol y el de aquellos individuos que la utilizan (Acuto 1999). De esta manera, ciertas características de la cultura material, condicionan y restringen algunas acciones entre cierto tipo de individuos. Al hacer esto, se establece una relación dialéctica entre el espacio social y las relaciones sociales: el espacio va construyendo a los individuos, quienes a su vez, construyen el espacio que los constituirá (Bourdieu 2007; Giddens, 2003; Acuto y Gifford, 2007). El espacio social es entonces, constitutivo y constituyente de la sociedad (Acuto y Gifford, 2007), motivo por el cual también es idiosincrático, es decir, caracteriza y es propio de cada una de ellas.

Si consideramos, como señala Eco (1975), que cualquier aspecto de la cultura puede convertirse en una entidad semántica, queda claro que la manera en la cual un grupo organiza su espacio se relaciona a un particular sistema de significados. De lo anterior se desprende que las dimensiones sintácticas del espacio, es decir, la relación entre sus componentes, nos pueden dar pautas acerca de sus significados y sobre el modo en el que los individuos las usan. El estudio de viviendas arqueológicas y sus patrones de organización como expresión material de la espacialidad (sensu Curtoni 2000 y Acuto 1999) se ha convertido, por lo tanto, en un tema de creciente interés en nuestra disciplina.

Considerando la importancia de las prácticas, muchos investigadores han destacado el valor de estudiar las experiencias sensoriales y corporales vividas por los grupos e individuos en el espacio (M. Merleau-Ponty; R. Johnston; M. Shanks; J. Thomas; C. Tilley; P. Wihtridge, etc.), por lo que otro tema tratado en las investigaciones es el de los fenómenos que ocurren en torno a su percepción. En el presente trabajo se considera que percibir de forma idéntica a los sujetos pretéritos es imposible ya que la interpretación siempre está cruzada por subjetividades enmarcadas en un tiempo-espacio particular. Debido a esto, sólo es posible reconstruir y comprender a grandes rasgos el sentido implícito de un espacio a través del reconocimiento de sus relaciones formales y considerando las formas posibles 
en las cuales emergieron los significados asociados a estos lugares (Criado Boado 1999; Thomas 2001). Esta situación inevitablemente lleva a que en este tipo de investigaciones existan indeterminaciones que nunca podrán resolverse, logrando sólo reconstruir narrativas parciales sobre ciertas dimensiones del pasado.

La Quebrada de Los Corrales constituye claramente un ejemplo de un paisaje donde una población temprana antropizó el espacio a través de su estructuración en varios sectores de ocupación. El estudio del paisaje en este trabajo será guiado entonces por la noción que los sitios deben ser interpretados en sí mismos y en el contexto general de la quebrada, analizando la relación entre los elementos del medio y las prácticas del pasado. Asimismo, para comprender la estructuración del espacio, se tendrán en cuenta cómo habrían sido vividos cotidianamente esos paisajes y otras alternativas que no tienen necesariamente un correlato material.

\section{Los patrones de asentamiento y el problema de la extrapolación}

Los primeros asentamientos netamente agro-pastoriles se establecen en diversos ambientes del NOA alrededor de 2100 años AP. Las aldeas presentaban generalmente dos tipos de instalación: 1) el disperso (cada vivienda se encontraba rodeada por sus terrenos de cultivo) y 2) el concentrado (las viviendas se agrupaban formando un pequeño poblado y se encontraban separadas de las áreas de cultivo) (Albeck 2000). En esta primera etapa, las viviendas fueron predominantemente de planta circular o elíptica, estando conformadas por varios recintos adosados que a veces se asociaban a un patio (Albeck 2000).

En cuanto a las zonas aledañas a El Infiernillo, el patrón de instalación dominante para el Primer milenio d. C. fue el disperso, como se conoce para los valles de Tafí (Berberian y Nielsen 1988; González y Núñez Regueiro 1960; Giani y Berberián 1999; Núñez Regueiro y García Azcárate 1996; Sampietro 2002), Amaicha (Aschero et al. 2007; Caria 2010; Somonte 2004), La Ciénaga (Cremonte 1996) y el pedemonte de Sierras del Aconquija (Scattolin 2007).

El modelo clásico de Tafí

El antecedente más cercano a El Infiernillo referido a tipologías y sistemas de asentamiento del Primer Milenio d. C., es el aportado por Berberián y Nielsen (1988) para el valle de Tafí. De acuerdo a este modelo, las evidencias arquitectónicas del sistema socio-cultural Tafí (ca. 300 a. C. -800 d. C.), conforman dos tipos de sistemas de asentamiento cronológicamente sucesivos: 1) Tafí I: caracterizado por unidades residenciales, de almacenaje y de procesamiento y consumo, dispersas en campos de cultivo; sociedades demográficamente poco densas, con bajo nivel de integración sociocultural, constituido por familias autosuficientes, y un explotación agrícola extensiva, y 2) Tafi II: representado por estructuras residenciales concentradas (aldeas) nítidamente separadas de las áreas de producción que se encuentran relacionadas con una población numerosa, de un nivel de integración socio-cultural relativamente alto y una explotación agrícola-pastoril intensiva y comunal. El tránsito a este segundo estadío podría estar vinculado a un desequilibrio entre la magnitud de la población, los recursos y la tecnología empleada para su explotación y habría sucedido hacia el $500 \mathrm{~d}$. C. (Berberian y Nielsen 1988; Cremonte 1996). 
Lo propuesto por estos autores supone entonces que las sociedades Tafí tuvieron una suerte de "evolución" unidireccional y progresiva que se expresó en un sistema de asentamiento sencillo que derivó en formas más complejas.

Actualmente, nuevas evidencias y fechados dan cuenta que la sucesión cronológica de los sistemas de asentamiento planteados por Berberián y Nielsen (1988) no sería tal. De acuerdo a Salazar (2007), los sitios grandes y concentrados serían los más tempranos, habiendo tenido su génesis como sitios discretos y diseminados donde se fueron agregando unidades a medida que se incrementaba la población y, como consecuencia de las tensiones generadas en torno a este nucleamiento, más tarde algunos miembros del grupo se habrían instalado en otros sectores generando nuevas unidades habitacionales dispersas.

El afán de organizar el complejo conjunto de evidencias materiales dejado por grupos sociales del pasado, ha derivado en la aplicación sistemática de modelos generales que han sesgado nuestra interpretación a tal punto de homogenizar la asombrosa diversidad que ofrecieron las prácticas humanas. Este es el caso del modelo de sistemas de asentamiento planteado por Berberian y Nielsen, que si bien funcionó para el valle de Tafí en algún momento, fue extrapolado al resto del NOA sin modificaciones.

Esto fue exactamente lo que sucedió al observar por primera vez la organización del espacio en El Infiernillo: al ver que existía una aldea concentrada, separada de las áreas de producción agrícola-pastoril, se pensó que los sitios de la Quebrada de los Corrales pertenecían a la fase Tafí II del modelo expuesto anteriormente. Actualmente las evidencias muestran que la quebrada habría estado habitada a comienzos del Primer Milenio y que sería contemporánea a los sitios adyacentes del valle de Tafí que fueron clasificados como Tafí I. Entonces, ¿cómo era posible que comunidades tan cercanas, ambas con un modo de vida campesino, pudieran manifestarse espacialmente de formas tan diferentes?

Otros autores se han preguntado acerca de la construcción de paisajes en relación a los espacios de residencia y de producción agrícola-pastoril durante el Primer Milenio d. C.

Para la faja pedemontana de la Sierra del Aconquija, Scattolin (2007) indaga sobre los tipos y rangos de variación entre los asentamientos del área. A través del análisis del grado de integración y densidad en cada sitio, concluye que, si bien todos tienen un patrón de asentamiento donde los recintos de vivienda se encuentran dispersos entre los de funcionalidad agraria, existen algunas variaciones de distribución y segregación entre ambos tipos de estructuras, resultando en organizaciones espaciales donde los núcleos habitacionales se encuentren más abirragados, como en el sitio Loma Alta, o menos densos y más separados de las áreas agrícolas, como sucede en Loma Redonda.

Para el Valle de El Bolsón y el área de Antofalla, también se ha tratado el tema de la articulación entre espacios agrícolas y domésticos (Quesada y Korstanje 2010; Quiroga y Korstanje 2007). Las investigaciones llevadas a cabo aquí, toman como eje de análisis las prácticas campesinas y su rol en el proceso histórico de formación de paisajes a través del estudio de casos. Si bien los sitios estudiados (La Mesada/Morro Relincho, El Alto El Bolsón, Antofalla, Tebenquiche Chico) comparten como característica la articulación entre casas y espacios agrícolas -como proponen los modelos para el Formativo- existen matices que enriquecen esta idea generalizada ya que, lejos de mostrar formas de espacialidad para un momento determinado, los paisajes deben pensarse como estructurados por las prácticas cotidianas (Quesada y Korstanje 2010). 
Pensada en el contexto local, la Quebrada de Los Corrales sin dudas se aparta de las formas convencionales de instalación para el Primer Milenio d. C., no sólo debido a que la articulación entre campos agrícolas y viviendas no es tan evidente como en otros asentamientos del período, sino también por la escala de estos espacios ${ }^{1}$. Entonces, si consideramos que dentro del modelo de "casas dispersas entre campos de cultivo" hay cierto grado de variabilidad, y que además existen otros sitios que se alejan de los patrones clásicos formativos (por ejemplo, Campo del Pucará en Andalgalá y Palo Blanco en Fiambalá, Catamarca), es incuestionable que existían formas diversas de construir paisajes en el Primer Milenio d. C.

Lo analizado nos llevó a pensar entonces que en realidad, la excepción era la regla, y es a partir de esta reflexión que debimos reformular aquella pregunta inicial que nos hicimos con respecto a la organización del espacio en la Quebrada de Los Corrales: ¿cómo no esperar que estos grupos humanos expresaran sus prácticas de maneras distintas? A su vez, esto derivó en la generación de otras preguntas: ¿qué nos estaba contando la organización del espacio residencial acerca de este grupo humano? ¿Porqué habían separado este sector de los productivos? Esta separación, ¿pudo haber implicado algo desde el punto de vista semántico? Y desde el punto de vista pragmático, esa separación ¿realmente existía?

Por lo antes mencionado, este trabajo tiene como objetivo principal comprender, con especial énfasis en el sector residencial, las condiciones que habrían generado la estructuración del espacio en la quebrada y las implicancias que pudo haber tenido a nivel semántico y práctico en el pasado.

\section{Metodología}

Se procedió a analizar el espacio habitacional de la Quebrada de Los Corrales en sí mismo y en relación a los componentes físicos del ambiente, a través del análisis de cartografía generada mediante un Sistema de Información Geográfico (SIG) ${ }^{2}$. Lo que se pretendía era que, sólo con las herramientas básicas ofrecidas por el software, se integrara y administrara información diversa para desarrollar distintos mapas que, combinados y superpuestos, permitieran establecer las vinculaciones entre diferentes variables espaciales. A su vez, la cartografía serviría como disparador para comprender cómo habría sido vivido en el pasado ese espacio físico y la influencia que tuvo esa experiencia en la conformación del paisaje arqueológico que hoy apreciamos.

Como base cartográfica, se utilizó una fotografía aérea de la quebrada ${ }^{3}$, donde fueron registradas diferentes entidades (cursos de agua, geoformas, estructuras arqueológicas, andenes de cultivo, corrales, núcleos habitacionales, etc.), transformando luego cada conjunto de éstas en un layer o tema dentro del SIG. Del mismo modo, tomando como base una imagen LIDAR, el programa realizó interpolaciones, obteniendo curvas de nivel, que a su vez permitieron generar mapas de elevación y pendientes. También se confeccionaron mapas de densidad edilicia (de viviendas y corrales) y de distancia (entre viviendas y campos de cultivo, y entre éstas y los cursos de agua). El desarrollo de las capas temáticas, permitiría luego superponer cada una para establecer relaciones entre las propiedades físicas del entorno y los rasgos arqueológicos, o entre rasgos arqueológicos en sí mismos. En este sentido se pudo observar, por ejemplo, la correlación espacial entre campos agrícolas y corrales; entre cursos de agua no-permanentes y áreas productivas; entre pendientes de $0^{\circ}$ y recintos habitacionales. 
En el campo, por otra parte, se realizó un relevamiento completo mediante GPS (con la función track) de estructuras residenciales, lo que permitió un mapeo rápido, digitalizado y georreferenciado de las mismas. De este modo, fue posible superponer estos datos con los mapas temáticos generados anteriormente. También se realizaron croquis, mediciones y fotografías de los núcleos habitacionales. A través de ambos registros, se pretendía determinar la morfología de las viviendas arqueológicas y el vínculo espacial entre los distintos núcleos habitacionales.

La generación de los mapas permitió, en primer lugar, explicitar ciertas relaciones entre los diferentes componentes materiales del paisaje y establecer las posibles condicionantes físicas que generaron la instalación de una aldea localizada al sur de la quebrada y separada de los campos de cultivo. En segundo lugar, sirvieron de instrumentos para considerar otras variables y dimensiones que supieron intervenir en la conformación del espacio y que escapan a la materialidad propiamente dicha.

Los datos obtenidos de la interpretación de los mapas fueron cruzados con otras evidencias de la quebrada como resultado de excavaciones, recolección de materiales de superficie y dataciones. Este análisis integral sirvió como punto de partida para pensar cómo ese paisaje habría sido construido, estructurado y vivido por las sociedades prehispánicas que habitaron la Quebrada de Los Corrales durante el Primer Milenio d. C.

\section{Resultados}

Hasta el momento, mediante el relevamiento de recintos habitacionales con GPS, fue posible mapear 85 núcleos habitacionales, entre completos y derruidos, que se agrupan a ambas márgenes del río de Los Corrales (PV1 hacia la derecha y PV2 hacia la izquierda) (Figura 3).

La configuración de estas estructuras residenciales, se asemeja al "patrón margarita" descripto por Berberián y Nielsen (1988) para el valle de Tafí: los núcleos en su mayoría son compuestos, es decir que están constituidos por recintos circulares centrales a los que se le adosan otros más pequeños también circulares (Figura 3). En la quebrada el patrón compuesto es el dominante, representando el $84,7 \%$ del total.

Acerca de las estructuras laterales adosadas, se debe resaltar el hecho que éstas presentan en su gran mayoría un acceso hacia el recinto central bien marcado por dos grandes rocas planas y paralelas. Todas las aberturas existentes se dan entre el recinto central y los adosados, no habiéndose hallado ninguna desde el recinto central hacia el exterior del núcleo residencial. Tampoco se encontraron aberturas desde el exterior de los núcleos hacia las estructuras adosadas, por lo que el acceso a éstas siempre está mediado por el recinto central.

Otra cuestión a destacar es que entre PV1 y PV2 no existen grandes diferencias desde el punto de vista estrictamente constructivo, ya que en todos los sectores se utilizaron los mismos materiales y técnicas para confeccionar los recintos. Sin embargo, cabe mencionar que en el sector denominado Taller, se encontraron recintos adosados con falsa cúpula, siendo entonces una característica exclusiva de este parte de PV1. A pesar de esta particularidad, no existen otros atributos arquitectónicos que permitan hacer una distinción tajante entre tipos constructivos para Puesto Viejo. 
Es importante mencionar que la distancia que separa un núcleo habitacional de otro varía entre 2 y $20 \mathrm{~m}$ por lo que en conjunto, y teniendo en cuenta las similitudes a nivel constructivo, las unidades habitacionales tienen el aspecto de un agrupamiento aldeano. Muy probablemente esta cercanía entre una estructura y otra haya generado una vinculación (corporal, visual, olfativa y auditiva) entre vecinos, mayor a la que se esperaría en sitios con un patrón disperso. Asimismo, la mayoría de los núcleos en PV tienen la particularidad de encontrarse ubicados sobre niveles aterrazados que aumentan paulatinamente de altura en sentido N-S. Estas terrazas habrían requerido de mantenimiento, lo que también podría haber reforzado los vínculos entre vecinos.

Por último, en PV no se observan espacios públicos delimitados arquitectónicamente al estilo de plazas, pero sí existen superficies libres que se esbozan entre estructuras y que pueden haber funcionado como espacios comunes para varios núcleos residenciales. Uno de esos espacios es el que se ha denominado "Taller". Éste presenta evidencias de actividades en estratigrafía que datan de ca.1750 AP, ca.3330 AP y ca.7420 AP (restos óseos faunísitcos; AMS (CASI-UGA)), por lo que se presume que este espacio fue de uso persistente a lo largo del tiempo (Martínez et al. 2011) (Figura 3).

En cuanto a los mapas de elevación y pendientes generados mediante SIG, éstos revelan que el $95 \%$ del sector residencial se ubica en los 3000/3100msnm y en lugares con $0^{\circ}$ de pendiente. Por otro lado, el $90 \%$ de las superficies de cultivo se hallan entre los $3000 \mathrm{y}$ $3300 \mathrm{msnm}$ y en pendientes de $0^{\circ}$ a $30^{\circ}$, mientras que los recintos con posible funcionalidad pastoril se ubican entre los 2800 y $3500 \mathrm{msnm}$. De éstos últimos, el $75 \%$ se presenta entre los 3100 y $3300 \mathrm{msnm}$, mientras que el $25 \%$ restante, en alturas mayores. En lo que respecta a las pendientes, el $90 \%$ de los corrales se encuentran entre los $10^{\circ}$ y $30^{\circ}$ (Figura 4)

Estos mapas nos muestran que existe una relación espacial entre los campos de cultivo y los recintos con probable funcionalidad pastoril. Se puede hipotetizar que esta relación es indicativa de la contemporaneidad entre ellos, dado que el guano de camélidos era usado en épocas prehispánicas para fertilizar campos de cultivo. Asimismo cabe la posibilidad de que estos corrales hayan sido usados de manera alternada como canchones o que parte de la producción agrícola haya sido destinada a especies forrajeras, como proponen Salminci et al. (2010) para Bajo del Coypar ${ }^{4}$. Estas ideas deberán ser corroboradas con futuras investigaciones.

Otro dato importante acerca del área de producción agro-pastoril, es su superficie de ocupación: la misma ha sido calculada en 477,3 ha. Se trata de datos realmente sorprendentes para el Primer Milenio d. C. dentro de la zona de estudio, teniendo en cuenta que no se conocen para sectores aledaños (Valle de Tafí, Amaicha, Santa María) sitios del mismo momento con campos agrícolas de esta escala.

En lo que respecta a los mapas de distancia, éstos muestran que las viviendas arqueológicas se encontraban a menos de $200 \mathrm{~m}$ de distancia de los ríos y a distancias de entre 400 y 5000 $\mathrm{m}$ de las áreas productivas. A su vez, el área agrícola estaba relacionada a cursos de agua semi-permanentes, hecho que refuerza la idea que los andenes eran regados con el agua de lluvia (Caria et al. 2010). Estos mapas dan cuenta entonces de la clara separación que existía entre el sector productivo y el residencial y que éste último, a su vez, estaba íntimamente relacionado con los cursos de agua permanentes -quizá uno de los factores condicionantes en su ubicación. 
Otro factor analizado en la quebrada fue la visibilización y la visibilidad (sensu Criado Boado 1999) del sector residencial. La visibilización se refiere a la manera en la cual es percibido un elemento arqueológico desde fuera, mientras que la visibilidad hace referencia a lo que se percibe desde éste.

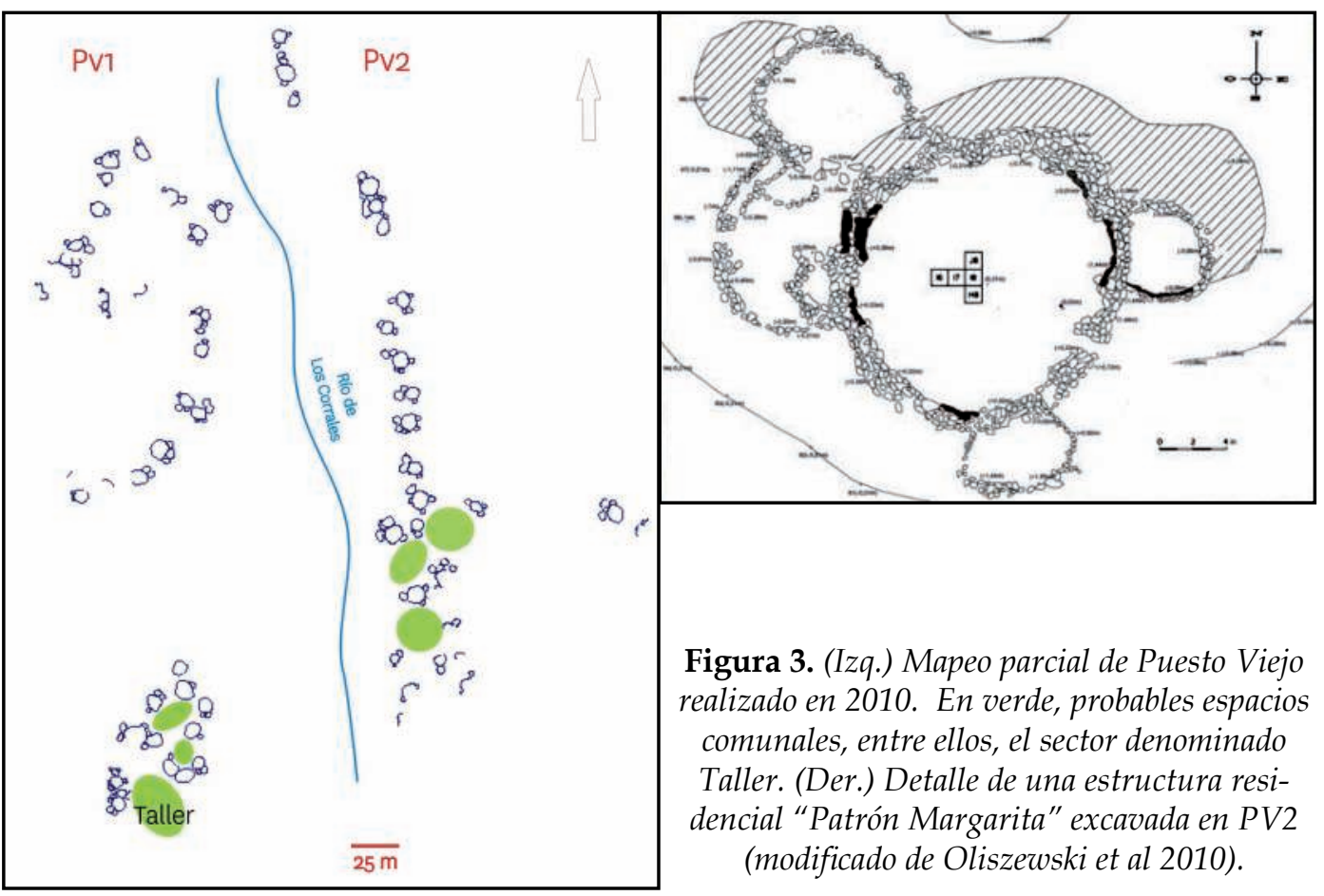

El análisis de la percepción visual tuvo como objetivo establecer qué elementos deseaba destacar u ocultar la población prehispánica de la quebrada. Debe tenerse en cuenta que las observaciones realizadas en el terreno se hicieron desde una percepción actual, es decir que estuvo atravesada no sólo por las perspectivas impuestas por nuestra cultura y disciplina, sino también por las limitantes propias del medio físico y los procesos post-depositacionales que modificaron los sitios. Dicho de otro modo, sólo se percibieron elementos que eran arqueológicamente susceptibles de ser observados, desde lugares por los que actualmente se puede transitar.

La visibilización del sector residencial (PV1 y PV2), desde el cauce del río, es total una vez que se llega al sector medio de la quebrada. No hubo, aparentemente, ninguna intención de ocultamiento por parte de las poblaciones prehispánicas. Por otra parte, la visibilización de Puesto Viejo es también excelente desde el área de los andenes (Figura 5), lo que refuerza la idea de que no existió una intención de invisibilizar el sector habitacional.

En cuanto a la visibilidad desde PV1, ésta es muy buena hacia todos los puntos cardinales, exceptuando el Oeste donde es nula por la presencia de una ladera muy alta, y el Sur, donde es menor por el cierre abrupto de la quebrada. Hacia el Norte se puede ver la quebrada perfectamente, al igual que los campos de cultivo (Figura 5), mientras que hacia el Este de PV1, y desde cualquier punto altitudinal, es posible observar toda la extensión de PV2, sin 


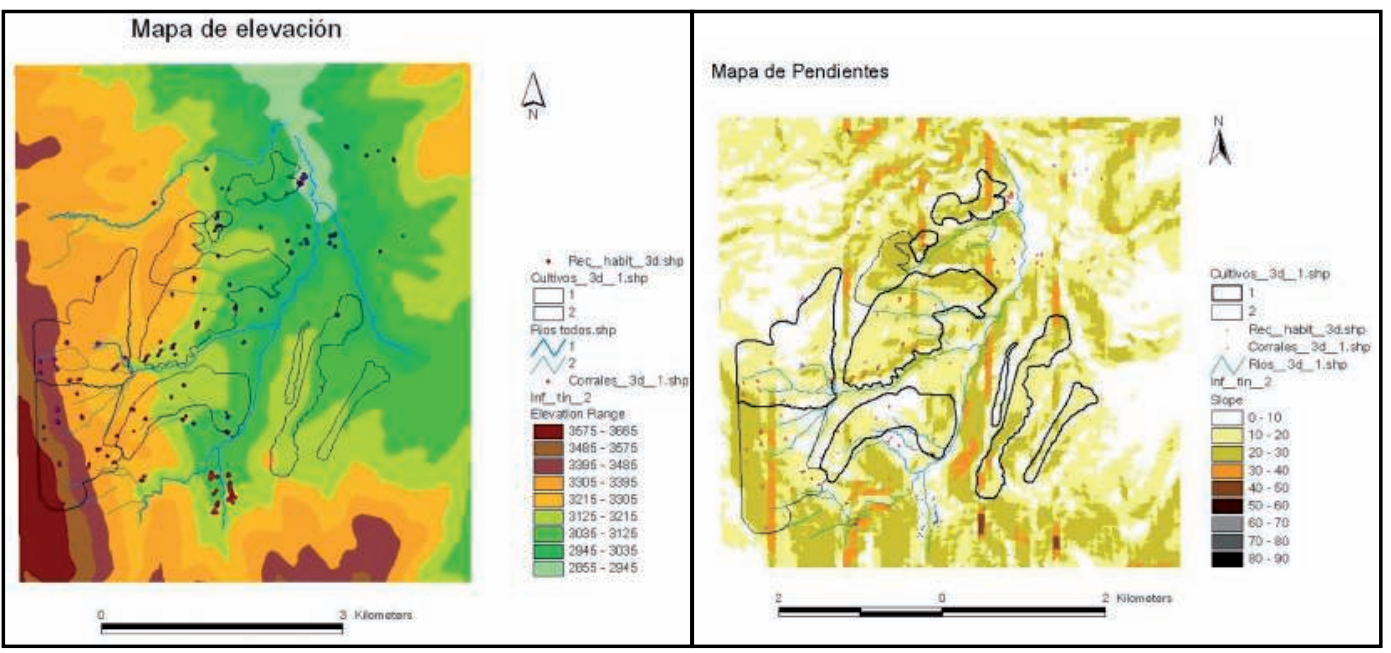

Figura 4. Mapas de elevación (izq.) y pendientes (der.), superpuestos con capas con información arqueológica (superficies con andenes; recintos habitacionales, corrales)

ningún tipo de obstáculo visual. Asimismo, y especialmente desde el sector del Taller, la visión hacia el Este es panorámica.

Por otro lado, la visibilidad desde PV2 es excelente hacia el Norte: se perciben perfectamente la quebrada y las áreas productivas. Del mismo modo, hacia el Oeste, puede verse toda la extensión de PV1. Sin embargo, hacia el Este la visión no es tan buena como la de PV1 ya que se encuentra cercana a una ladera. Por último, al Sur la visión se dificulta al igual que en PV1.

\section{Discusión y consideraciones finales}

El sector residencial visto desde la quebrada

Desde el punto de vista material, la configuración del espacio de la Quebrada de Los Corrales nos habla de una sociedad que para el Primer Milenio d. C. separó su vida doméstica de aquella vinculada con las tareas de producción agrícola y pastoril. Esta separación se observa claramente en la cartografía, la que muestra una aglomeración de núcleos residenciales que forman un poblado-Puesto Viejo- ubicado a distancias de $1 \mathrm{Km}$ en promedio, de las áreas productivas. Esta segregación también se percibe corporal y visualmente en el terreno mismo.

El sector de viviendas, conformado por 85 unidades, se encuentra sobre superficies casi sin inclinación, a alturas promedio de $3100 \mathrm{~m}$ y a cortas distancias de fuentes permanentes de agua (a menos de $200 \mathrm{~m}$ ). No podemos, sin embargo, tomar estas variables puramente topográficas como únicas causales de la particular ubicación de los núcleos habitacionales, pues en otros sectores de la quebrada encontramos lugares con las mismas características y sin evidencias arquitecturales domésticas.

Entonces, ¿qué particularidades tiene el sector meridional de la quebrada que estimuló el asentamiento de poblaciones tempranas separadas de sus áreas agrícola-pastoriles? Si 


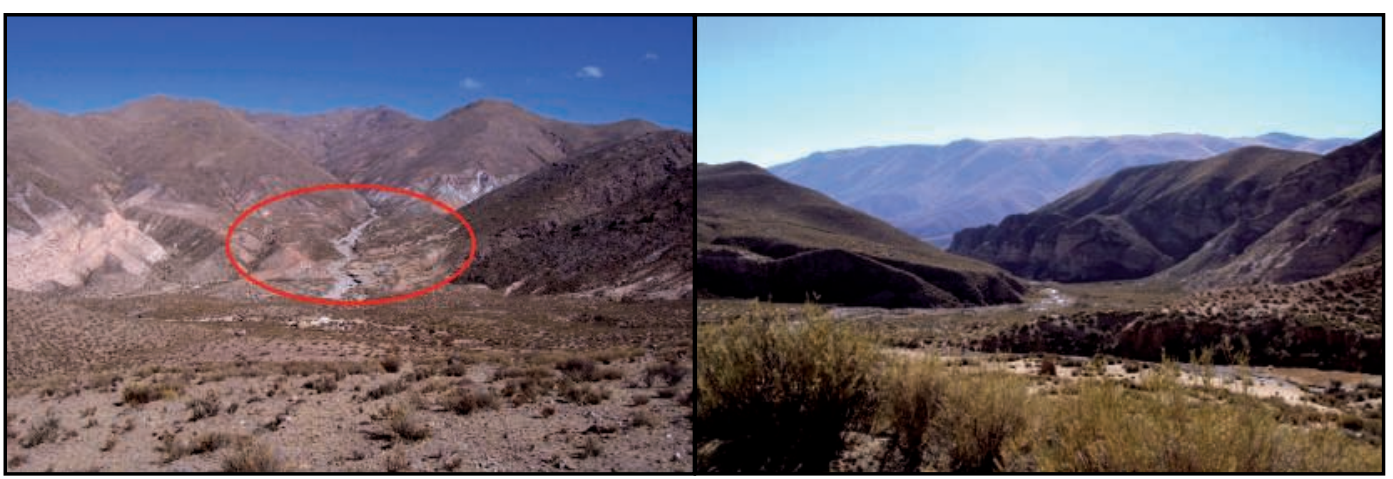

Figura 5. (Izq.): Puesto Viejo (resaltado en rojo) visto desde las áreas agrícolas. (Der.): visibilidad hacia el Norte desde Puesto Viejo 1.

nos centramos en los elementos físicos o ambientales, podemos destacar que este sector se distingue por ser un área donde la quebrada se ensancha dejando un espacio abierto de importantes dimensiones. Es también el único lugar donde los depósitos de remoción en masa conformaron pequeñas "mesetas" que son bajas para permitir el fácil acceso al agua, pero al mismo tiempo lo suficientemente altas para estar protegidas durante posibles crecidas del río.

Si bien estas características son relevantes a la hora de optar por un lugar para el asentamiento, deben tenerse en cuenta otras variables que actuaron en esa elección y que no implicaron necesariamente acciones pensadas, proyectadas y conscientes. Se trata de aquellos factores que nacieron de la experiencia corporal de los lugares. De acuerdo a lo planteado por Tilley (2004), nuestro cuerpo sintiente es el que nos conecta con el mundo, el que nos permite conocer lo que es un lugar y un paisaje. Sin embargo, esa conexión con el espacio está fuertemente condicionada por la bilateralidad básica del cuerpo (arriba/abajo; derecha/ izquierda; adelante/atrás). Por lo tanto, la experiencia del mundo en términos duales, es la base fundamental a través de la cual aprehendemos, ordenamos y semantizamos al espacio. En este sentido, la organización de Puesto Viejo en dos sectores puede ser interpretada como un signo, índice del ordenamiento de los lugares y sus significados, derivado de la experiencia y la dinámica propia de la vivencia cotidiana de la quebrada y su río.

Otro tema que debe tenerse en cuenta para la ubicación de las viviendas en este sector, es la "abertura" de la quebrada que permite tener una visibilización perfecta de los sitios habitacionales desde la cuenca del río. De la misma manera, desde las viviendas se tiene una buena panorámica de la quebrada, convirtiéndose así en un lugar de privilegio para la visibilidad.

Por lo antes mencionado, se considera que la elección del lugar de residencia en la quebrada de Los Corrales se debería entender como el resultado de una conjunción de acciones conscientes y con fines prácticos- por encontrarse el asentamiento en lugares protegidos, de fácil acceso y cercanos a cursos de agua -, como inconscientes -al optar por un espacio altamente visible, que su vez ofrecía las condiciones para manifestar una experiencia dual del mundo circundante. De este modo, el espacio en la quebrada se habría configurado como un pequeño cosmos; como un sistema de lugares significativos que ofreció posibilidades de identificación (Norberg Schulz 1972). 
Otra relación que queda evidenciada en el análisis de los mapas, es aquella que se da entre los campos de cultivo y los recintos con probable funcionalidad pastoril. Esta relación podría estar vinculada a un tema de orden funcional, pues quizá el guano de los camélidos era utilizado para fertilizar los campos sobre los que se encontraban los corrales. Incluso puede plantearse que una parte de la producción vegetal haya estado destinada como forraje para los animales que se criaban. Del mismo modo, cabe la posibilidad que estas estructuras sirvieran alternadamente como corrales y canchones de cultivo. Estas suposiciones deberán corroborarse con futuras investigaciones, pero lo que sí queda claro desde el análisis espacial, es el fuerte nexo que existía entre la actividad agrícola y pastoril, y que éstas se practicaban en escenarios distintos a los de la vivienda.

Alejándonos de las discusiones en torno a cuestiones empíricamente verificables y considerando que los paisajes son tanto estructurados por y estructurantes de las prácticas ¿qué podría haber implicado a nivel semántico y pragmático la separación de las áreas domésticas y productivas?

Se pueden plantear dos hipótesis. La primera sería considerar que la separación de las áreas se debió a una cuestión de orden semántico, es decir, que culturalmente las actividades domésticas y las agrícolas/ pastoriles se percibían como separados en campos de significación distintos e incluso opuestos. Estas sociedades, por lo tanto, habrían estructurado su espacio de acuerdo a las nociones de Aldea vs. Campo, lugares que al constituirse en escenarios de prácticas cotidianas específicas, reprodujeron las condiciones que engendraron la división entre ellos.

La segunda hipótesis, por otra parte, plantea la posibilidad de que estos escenarios manifestados de forma separada en el espacio, estuvieran vinculados a través de las prácticas en el pasado, sin que esto haya tenido un correlato material. Si bien hay una separación física entre lo doméstico y lo productivo, la cantidad de espacios dedicados a la agricultura y al pastoralismo nos habla de una sociedad íntimamente ligada a las actividades del campo. De este modo, la gente que habitaba Puesto Viejo, cotidiana y cíclicamente habría trabajado las tierras como medio para sustentar la familia y la vivienda, entrelazando de este modo ambas esferas en la práctica.

Esta relación íntima entre el campo y el poblado quizá no pueda verse reflejado a nivel espacial, sino a nivel visual, ya que desde PV la visibilidad hacia los campos de cultivo es perfecta y viceversa. La imagen mutua y constante que experimentaban las personas -de andenes con trabajadores, de viviendas habitadas y de un poblado transitado por personasfue quizá la forma en la que se expresaron los lazos que existían entre la casa y el campo. De este modo, los habitantes de Puesto Viejo, lejos de "percibir" ese paisaje como un conjunto de elementos pasivos, lo experimentaban como una trama de lugares significativos en la cual estaban insertos y con los cuales formaban una comunión (Thomas 2001).

Puesto viejo: una aldea temprana

Del análisis del relevamiento de recintos habitacionales, se interpreta que existió una clara intención por parte de la población de la quebrada de organizar sus núcleos domésticos en un poblado. Éste se encuentra compuesto por módulos funcionales (sensu Nielsen, 2001) ${ }^{5}$ que se encuentran separados unos de otros por espacios vacíos de $12 \mathrm{~m}$ en promedio, y que se reiteran a lo largo de ambas márgenes del río. 
La cuantificación de tipos de núcleos mapeados, revela que el patrón dominante de Puesto Viejo es el compuesto, es decir que son recurrentes aquellas estructuras que poseen un recinto central con más de un recinto adosado a su alrededor.

El recinto central de estas unidades, tiene una posición fundamental ya que a partir de él crece y se configura el núcleo residencial. Asimismo, constituye el nexo de comunicación con los recintos adosados, por lo que se convierte en un lugar de paso obligado. Si a esto le sumamos los datos provenientes de excavación que indican que en este espacio se llevaban a cabo actividades domésticas (Oliszewski et al 2010), el patio se convierte en el eje principal y compartido del hogar. Como se ha constatado en PV1, estos espacios también eran altamente significativos ya que eran elegidos para el entierro de personas. Los antecedentes para el Primer Milenio d. C. nos hablan de que en zonas próximas (Valle de Tafí y Amaicha), en sitios con estructuras patrón margarita, las prácticas de inhumación eran semejantes a las de la quebrada, es decir, las inhumaciones se realizaban en los recintos centrales(Aschero y Ribotta 2007; Berberián y Nielsen 1988; Chiappe Sánchez 2007; Sampierto Vattuone 2002; Salazar 2010).

Si bien la estructuración de los núcleos habitacionales es centrípeta, dándonos la idea de una dimensión de intimidad vivida por sus residentes, volcadas hacia el interior y sin comunicación aparente con el exterior por la falta de aberturas, habría coexistido una esfera de acción articulada en torno a lo supradoméstico y a la integración extra-familiar. Ésta se vería expresada espacialmente en la aglomeración de núcleos que forman un poblado y por la presencia de campos agrícolas con andenerías que podrían haber sido construidos y compartidos por más de un grupo familiar. Del mismo modo se evidencia la presencia de espacios abiertos, que carecen de demarcación arquitectónica, pero que se esbozan entre estructuras y que pueden haber funcionado como lugares comunes a varios grupos corresidentes. Cabe destacar que uno de estos lugares es el llamado "Taller". Si bien éste pertenece a momentos anteriores a la instalación de grupos agro-pastoriles (ca. $3300 \mathrm{y} \mathrm{ca}$. 7420 años AP), aquí se realizaban actividades probablemente grupales (como la confección de artefactos líticos y la molienda de vegetales) que habrían hecho de este espacio un lugar de encuentro y vínculo. A su vez, nuevos contextos de hallazgo obtenidos de estratigrafía, y contemporáneos a las estructuras del Primer Milenio, indicarían el uso persistente de este lugar. Si bien con el paso del tiempo pudieron haber cambiado las actividades desarrolladas allí, es altamente factible que este espacio fuera un lugar de uso por fuera de la vivienda, accesible a toda la comunidad.

A nivel de las prácticas, el compartir espacios comunes y la cercanía entre estructuras, habrían fomentado los lazos de unión que superaban los límites de la familia. Incluso la circulación obligada entre las viviendas, para ir de un lugar al otro del sitio, habría producido un efecto muy distinto al que experimentaban aquellas poblaciones con un patrón de asentamiento disperso: los habitantes de una aldea se cruzan por los senderos, oyen las actividades que realizan los vecinos, sienten las comidas que se están preparando. También debe mencionarse el hecho que las viviendas se ubican en niveles aterrazados, lo que habría implicado el mantenimiento de éstas por parte de las familias asentadas allí. En fin, en Puesto Viejo se compartían experiencias cotidianas, que creaban y reproducían las condiciones para que existiera una integración a nivel de aldea, que a su vez habría fomentado la creación y persistencia de campos agrícolas compartidos y separados del poblado. 


\section{A modo de conclusión}

Lejos de asemejarse a los sitios de la misma época del área, la estructuración espacial de la Quebrada de Los Corrales se presenta como una variación a los modelos planteados para el Primer Milenio d. C., incluso aquellos que se desarrollaron para zonas cercanas (i.e. Berberián y Nielsen 1988, para Tafí).

Esto nos invita a reflexionar acerca de los modelos unívocos tradicionalmente mantenidos por nuestra disciplina y que se aplican de forma automática y sin variaciones a zonas distintas a aquellas para las cuales se habían planteado originalmente. La aplicación de éstos invisibiliza la diversidad que realmente existió entre las poblaciones del pasado, por lo que cualquier producción cultural (sea la espacialidad, la producción artesanal...) debería siempre ser entendida en su contexto particular de elaboración y uso. Si bien algunas cuestiones eran compartidas por distintas poblaciones del Primer Milenio d. C., como las formas de inhumación, las técnicas constructivas, etc., esto no debe llevarnos a homogenizar las prácticas de los grupos prehispánicos.

La idea es que para estos momentos, existió un modo de vida que giraba en torno a las actividades agro-pastoriles, pero que este lazo con lo agrario pudo tomar, de acuerdo al contexto de las prácticas, diferentes matices para un mismo momento. De esta manera, las comunidades que habitaron la Quebrada de Los Corrales estructuraron su espacio de forma distintiva para el lugar y la época: constituyeron el sector residencial netamente separado de las aéreas de producción agrícola-pastoril, lo que a su vez habría fomentado la producción y reproducción de lazos comunitarios.

\section{Agradecimientos}

El presente trabajo no podría haberse realizado sin el apoyo de mi amiga y directora, Nurit Oliszewski. Siempre atenta y respetuosa, nos inculca el amor por la investigación.

Agradezco igualmente a todo el equipo de El Infiernillo porque hace de cada campaña una aventura memorable.

Finalmente a Matías, por haber llenado mi mundo de color.

\section{Notas}

${ }^{1}$ Si bien el sitio Laguna Blanca (Dpto. Belén, Catamarca) presenta grandes extensiones agrícolas para la época, en las localidades arqueológicas adyacentes a El Infiernillo, no las hay.

2 Programa ArcView 2.3a

${ }^{3}$ Fotografía aérea en blanco y negro de El Bracho - Alumbrera (corrida no8), escala 1:20.000, de la Minera La Alumbrera (1995). La misma fue digitalizada y georreferenciada para su uso en el SIG.

${ }^{4}$ Poblado del $2^{\circ}$ milenio d. C. con un complejo sistema de andenería asociado, ubicado en Antofagasta de la Sierra (Catamarca).

${ }^{5}$ Para el autor la vivienda se refiere al conjunto mínimo de espacios, que conforman una unidad discreta y funcionalmente integrada y que da cuenta de las actividades de residencia en una localidad, durante un período más o menos prolongado.

\section{Bilbiografía Citada}

Acuto, F.

1999 Paisaje y dominación: la constitución del espacio social en el imperio Inka. Sed Non Satiata. Teoría Social en la Arqueología Latinoamericana Contemporánea. Pp.33-75. 
Acuto, F. y C. Gifford

2007 Lugar, Arquitectura y narrativas del poder: relaciones sociales y experiencia en los centros inkas del Valle Calchaquí. Arqueología Suramericana Vol.3 N.2: 135 -161

Albeck, M. E

2000 La vida agraria en los Andes del sur. Nueva Historia Argentina. Los pueblos originarios y la conquista. Editorial Sudamericana. Tomo I. Pp: 187-228. Buenos Aires.

Aschero, C y E. Ribotta

2007Usos del espacio, tiempo y funebria en El Remate(LosZazos, Amaicha del Valle, Tucumán). Paisajes y procesos sociales en Tafi del Valle. (ed. por P. Arenas, B. Manasse y E. Noli) Pp.: 79-94. Tucumán.

Ashmore, W y A.B. Knapp

2000 Archaeological Landscapes: Constructed, Conceptualized, Ideational. Archaeologies of Landscape. Contemporary Perspectives. (ed. por W. Ashmore y B.Knapp) Pp: 2-30. Gran Bretaña.

Berberián, E.E y L. Giani

2001 Organización intrasitio y macroespacial en el Formativo del valle de Tafí (Tucumán). Actas del XIII Congreso Nacional de Arqueología Argentina. I: 409-415

Berberian, E.E y A. Nielsen

1988 Sistemas de asentamiento prehispánicos en la etapa Formativa del Valle de Tafí (Pcia. de Tucumán - República Argentina). Sistemas de asentamiento prehispánicos en el Valle de Tafí. (ed. por Berberián, E.E.). Pp. 21-51. Córdoba.

Bourdieu, $\mathrm{P}$

2007 Espacio social y poder simbólico. Cosas Dichas. Ed. Gedisa. Barcelona

Caria, $\mathrm{M}$

2010 Agricultura Arqueológica de LosSitios “El Divisadero" y “Yasyamayo” (Cumbres CalchaquíesTucumán-Argentina). Actas del XVII Congreso Nacional de Arqueología Argentina V: 2021-2026

Caria, M.A., J.G. Martínez y N. Oliszewski

2006 Geomorfología y Arqueología dela Quebrada del Río de los Corrales (El Infiernillo-Tafí del ValleTucumán-Argentina). Actas del III Congreso Argentino de Cuaternario y Geomorfología I: 145-154.

Caria, M.A., N. Oliszewski, M. Pantorrilla y J. Gómez Augier

2007 Relevamiento y clasificación del sistema agrícola prehispánico en la Quebrada del Río Los Corrales (El Infiernillo-Tafí del Valle-Tucumán). Número Especial de Revista Pacarina. Resúmenes ampliados XVI Congreso Nacional de Arqueología Argentina. I: 49 -54.

Caria, M.A, N. Oliszewski, J. Gómez Augier, M. Pantorrilla y M. Gramajo Bühler.

2008 Formas y espacios de las estructuras agrícolas prehispánicas en la Quebrada del río de Los Corrales (El Infiernillo-Tucumán). Arqueología de la agricultura: casos de estudio en la región andina argentina. (ed. por M. A. Korstanje y M. Quesada). Pp: 98-111

Chiappe Sánchez, N.R.

2007 Sobre la Construcción Social de la Muerte. Las Prácticas Funerarias en un Sitio Agroalfarero Temprano: Bajo de Los Cardones -Amaicha del Valle, Tucumán-. Tesina de grado. Facultad de Ciencias Naturales e IML, UNT. Tucumán. 
Cremonte, M. B.

1996 Investigaciones Arqueológicas en la Quebrada de la Cienaga (Dpto. Tafí, Tucumán). Tesis Doctoral. San Salvador de Jujuy, Jujuy, Argentina

Criado Boado, F.

1999 Del Terreno al Espacio: Planteamientos y Perspectivas para la Arqueología del Paisaje. CAPA. Criterios y Convenciones en Arqueología del Paisaje. 6: 1-82

Cruz, H; E. Mauri y J. Martínez.

2009 Reconocimiento de fuentes de aprovisionamiento prehispánicas de materias primas líticas prehispánico en la Quebrada de Los Corrales (El Infiernillo, Tucumán, Argentina). Serie Monográfica y Didáctica 48: 111

Curtoni R. F.

2000 La percepción del paisaje y la reproducción de la identidad social en la región pampeana occidental (Argentina). TAPA. Paisajes culturales sudamericanos. De las prácticas sociales a las representaciones. 19: 115-125

Di Lullo, E.

2008 Cueva de Los Corrales 1, un locus multifuncional. La contrastación de hipótesis con un SIG. Libro de Resúmenes XVI Jornadas de Jóvenes Investigadores AUGM: 291.

Giani L. M. y E.E. Berberián

1999 Consideraciones acerca de la variabilidad formal en el diseño de las plantas de arquitectura en el NOA durante las etapas Formativas y de Desarrollos Regionales. Actas del XII Congreso Nacional de Arqueología Argentina. I: 83-88.

Giddens, A.

2003 La constitución de la sociedad. Bases para la Teoría de la Acción. Amorrortu Editores. Buenos Aires.

González, A. R. 1998 Arte Precolombino. Cultura La Aguada, Arqueología y Diseños. Buenos Aires.

2004 La Arqueología del Noroeste Argentino y las Culturas Formativas de la Cuenca del Titicaca. Relaciones de la Sociedad Argentina de Antropología. XXIX: 7-38.

González, A. R. y V. A. Nuñez Regueiro

1960 Preliminary Report on archaeological research in Tafí del Valle, N. W. Argentina. Akten des 34. Internationales Amerikanistenkongresses : 485 - 496.

Gramajo Bühler, C. M.

2009 Primera Caracterización del Conjunto Cerámico de La Quebrada de Los Corrales (El Infiernillo, Tucumán). Serie Monográfica y Didáctica 48:121

Martínez, J., Mauri, E., Mercuri, C., Caria, M. y N. Oliszewski

2011 Paleo-tucumanos a la vista !!!: las evidencias más tempranas de ocupaciones humanas hasta el momento en la Quebrada de Los Corrales y provincia de Tucumán. Serie Monográfica y Didáctica. 49:127. 
Mauri, E. P y J. G. Martínez

2009 Análisis de Puntas de Proyectil Líticas de la Quebrada de Los Corrales (El Infiernillo, Tucumán) y sus Implicancias Tecno-tipológicas y Cronológicas. Serie Monográfica y Didáctica. $48: 13$

Martínez, J.G, E.P. Mauri, C. Mercuri, M. Caria y N. Oliszewski

2011 Ocupaciones humanas tempranas en el Centro-Oeste de Tucumán...hay vida más allá del Formativo? Poblaciones humanas y ambientes durante el Holoceno medio. Taller de Arqueología: 119-121.

Muntaner, A. C

2009 Identificación Anatómica y Estimación de Sexo, Edad y Estatura de un Enterratorio Humano en la Quebrada de Los Corrales (El Infiernillo, Tucumán). Serie Monográfica y Didáctica. 48: 121.

Nielsen, A.

2001 Evolución del Espacio Domestico en el Norte de Lípez (Potosí, Bolivia): ca 900 - 1700 d. C. Estudios Atacameños. 021: 41-62.

Núñez Regueiro, V. A.

1998 Arqueología, Historia y Antropología de los Sitios de Alamito. Facultad de Ciencias Naturales e IML, UNT. Tucumán.

Núñez Regueiro, V. y J. García Azcarate.

1996 Investigaciones arqueológicas en El Mollar, Tafí del Valle, Pcia. de Tucumán. Actas y Memorias del XI Congreso Nacional de Arqueología (13a parte) Revista del Museo de Historia Natural de San Rafael. XXV (1/2): 87-97.

Oliszewski , N

2011 Ocupaciones prehispánicas en la Quebrada de Los Corrales, El Infiernillo, Tucumán (ca. 2500-600 años ap). Comechingonia. 14: 127-144.

Oliszewski, N., G.A. Arreguez, H. Cruz, E. Di Lullo, C.M. Gramajo Bühler, E.P. Mauri, M.M. Pantorrilla Rivas y M. G. Srur.

2010a Puesto Viejo: una aldea temprana de altura en la Quebrada de Los Corrales (El Infiernillo, Tucumán). Actas del XVII Congreso Nacional de Arqueología Argentina. IV: 1697-1702.

Oliszewski, N.; C.M. Gramajo Bühler, E.P. Mauri, G.E. Miguez, A.C. Muntaner y M. M. Pantorilla Rivas.

2010b. Caracterización de un enterratorio humano en la Quebrada de Los Corrales (El Infiernillo, Tucumán). Revista Intersecciones en Antropología. 11: 315-319.

Oliszewski, N., J. Martínez y M. Caria

2008 Ocupaciones prehispánicas de altura: el caso de Cueva de los Corrales 1 (El Infiernillo, Tafí del Valle, Tucumán). Relaciones de la Sociedad Argentina de Antropología 33:209-221.

Quesada, M.N

2007 Paisaje Agrarios del Área de Antofalla. Procesos de Trabajo y Escalas Sociales de la Producción Agrícola. (Primer y Segundo Milenio). Tesis Doctoral. Facultad de Ciencias Natural y Museo. Universidad Nacional de La Plata. Argentina. 
Quesada, M.N y M.A. Korstanje

2010 Cruzando estructuras: el espacio productivo y su entorno percibido desde las prácticas cotidianas. El hábitat prehispánico. Arqueología de la arquitectura y de la construcción del espacio organizado (ed. por M. E. Albeck, M. C. Scattolin y M. A. Korstanje), pp. 119-147. Salta

Quiroga, L y M. A. Korstanje

2007Arqueología del Campesinado en el Valle del Bolsón. Producción y Residencia como Líneas de Análisis para una Escala de Larga Duración. En prensa en: El uso de SIG en la arqueología sudamericana. B.A.R. International Series. Oxford, Inglaterra.

Ruiz, M.S.

1998 Los Inkas. Espacio y Cultura. EDUJNU, Jujuy.

Salazar, J

2007 Reproducción social doméstica y asentamientos residenciales entre el 200 y 800 d.C. en el Valle de Tafí, Provincia de Tucumán. Comechingonia Virtual. 1:52-66.

2010 Viviendo con los ancestros. Un análisis de las inhumaciones en contextos domésticos del primer milenio en el valle de Tafí. Actas del XVII Congreso Nacional de Arqueología Argentina. II: 635

Salminci, P. M., P. Tchilinguirian y D. E. Olivera

2010 ¿Cultivo de Alimentos o Producción Forrajera? Agricultura Bajo Riego Durante el Periodo Tardío en Antofagasta de La Sierra, Catamarca. Jornadas de Arqueología de la Alimentación. Cultura material, prácticas y significados: 80-81

Sampietro Vattuone. M.M.

2002 Contribución al conocimiento Geoarqueológico del Valle de Tafí, Tucumán (Argentina). Tesis Doctoral en Arqueología. Facultad de Ciencias Naturales e IML UNT, Tucumán.

Scattolin, C.

Scattolin 2007. Un examen del espacio residencial y productivo en el Aconquija. Shincal. 7:135-149

Somonte, $\mathrm{C}$.

2005 Uso del Espacio y Producción Lítica en Amaicha del Valle (Departamento Tafí del Valle, Tucumán). Intersecciones en Antropología. 6: 43-58.

Thomas, J.

2001 Archaeologies of Place and Landscape. Archaeological Theory Today. Polity Press. Pp. 165-186. Cambridge.

Tilley, C

2004 The materiality of stone. Berg. New York. 